\title{
KURUCU ANLAŞMALAR ve ANLAŞMALARIN ANAYASA HUKUKU KARAKTERI
}

\author{
Prof. Dr. Füsun ARSAVA*
}

ATAD sadece AET anlaşmasını (bugün AT anlaşmasını) Topluluğun anayasal belgesi olarak kabul etmektedir. Divan Avrupa Ekonomik alanı ile ilgili 14.12.1991 tarihli (Rs. C-1/91, Slg. 1991, I-6079 = EuGR2 1992, 67) danışma gorüşünde ve 23.4.1986 (Rs. 294/83, Slg. 1986, 1339 = EuGR2 1987, 383, Nr. 99) tarihli "Les Verts" karanında, bu anlaşmanın her ne kadar bir DH anlaşması formu içinde ortaya çukmış olsa da hukuk topluluğunun anayasal belgesini teşkil ettiğini ifade etmiştir.

Üç anlaşmadan sadece birine yapılan bu atıf, AT anlaşmasının genel nitelił̌inden, Topluluklann şüphesiz en önemli anlaşması olmasından ileri gelmektedir. Bu atfin yer aldığı bỏlümde yer alan açıklamaya karşın anlaşmaların tümünün, her ne kadar AT anlaşmasının fundemental karakteri 1993'de yürürlüğe giren deǧişiklikten sonra daha açlk olarak ortaya çıkmışsa da, sadece AT anlaşmasının değil, Topluluk anayasasının parçalan olarak görülmesi gerekir.

Bunun ótesinde Topluluk anayasası sadece kurucu anlaşmalardan ibaret değildir. Muayyen temel öneme sahip, üye devletler hukuk düzenlerinde ortak olarak yer alan genel hukuk prensipleri de Topluluk anayasının parçasıdır.

Topluluk anlaşmalarının Topluluk hukuk düzeninde hiyerarşik bir yeri vardır. Divana verilen yetkilerin önemli bir kısmı Topluluk anlaşmalarının oncelił̧inin korunmasına ilişkindir. Bu denetim 173. md. ışı̆̌nda Topluluk organlarının tasarruflarının hukuka uygunluk denetimi seklinde olabilir (iptal davası); Topluluk organlanıı tasarruflarının geçerliliği için açılan önkarar davası (md. 177) şeklinde olabilir ve 184. md. göre hukuka aykunlik defi ş̧eklinde olabilir.

Topluluk organlannın hukuka uygunluk denetimi hem Topluluk tasarruflanının anayasaya uygunluğu, hem de yönetimin yasalara bağlılığı denetimini kapsamaktadır. Topluluktaki yetki ayrılı̆̆ının özelliği nedeniyle ve tüm Topluluk tasarruflarının hukuka uygunluk denetimi için hukuki ölçülerin aynı olması nedeniyle bu iki boyut arasında bir sınir çizilmesi çok zor olmaktadır. Bu durumu 22.10.1987 tarihli kararında -Foto-Frost

\footnotetext{
* A.U. Siyasal Bilgiler Fakültesi Oğretim Uyesi.
} 
davas1- Divan gostermiştir. (Rs. 314/85, Slg. 1987, 4199 =, EuGRZ 1990, 373, Nr. 180).

Divan bu kararında ulusal mahkemelerin Topluluk organlarının tasarruflarını geçersiz kılamayacağını saptamıştır. Bu sonuç ilk bakışta (ulusal yargının Topluluk tasarruflarnnın yorum ve geçersizlik denetiminde sahip olduğu fonksiyonlarla ilgili olarak) 177. md. lafzından sapmaktadır. Ancak Divan karanını iki gerekçe ile desteklemiştir. Bunlar, Topluluk hukuk düzeninin birliğinin korunması ve anlaşmalar tarafından yaratılan yargı sistemine bağlılık gereksinimidir.

Divanın geçersizliğin saptanması konusunda yegane yetkili olma iddiası arkasında bu prosedürü bir anayasaya uygunluk denetimi olarak gormesi yatmaktadır. Bu kararnn genel karaktere sahip bir norm ile ilgili olarak değil, idari kararla ilgili olarak verildił̧ini unutmamak gerekmektedir. Anlaşma genel geçerliliǧe sahip tasarrufların ve bireysel tasarnufların iptali bakımından açık bir ayrım yapmaktadır. (173. md.)

Tüzüklerin iptalini talep etme yetkisi, genel geçerli norm olması nedeniyle sadece Topluluk uyesi devlet ve Topluluk organlarına aituir; ancak bu durum ozel kişilerin kendilerini muhatap alan bireysel tasarrufa esas olan genel geçerlilige sahip bir normun anayasaya aykırılığını iddia edebilmesini engellemez. 184. md. hukuki uyuşmazlıktaki tarafların tüzügün uygulanmamasinı talep etme hakkını kabul etmektedir. Diger taraftan tüzügün uygulanmamasını ulusal mahkeme önünde de talep etmek mümkündür. Ulusal mahkeme bir tüzügüun geçerlilik denetemini ơnkarar davası olarak Divana arzedebilir:

\section{Topluluk içinde yetki sorunu}

Kurucu anlaşmaların, çeşitli organların yetkilerini düzenleyen hükümlerinin anayasa hukuku karakteri son on yılda çeşitli yetki uyuşmazlıkları nedeniyle Divan onuinde gündeme gelmiştir.

Bu yetki uyuşmazlıklarının odağını kural olarak tasarruflara esas olan hukuki dayanağın seçimi oluşturmuştur.

Bu uyuşmazlıkların karara bağlanması için ơzel bir yöntemin öngorrülmemesi nedeniyle, iptal davası ve hareketsizlik davası, Komisyon ve Konsey; Konsey ve Parlamento yahut üye devletler ve Topluluk organlan arasında açılan dava türleri kullanılmıştır.

\section{Üye devletlerin ve Topluluğun yetkileri}

Topluluklar tüm özelliklerine rağmen uluslararası bir kuruluştur ve üye devletlerden farklı olarak genel yetkiye sahip değildir; kurucu anlaşmaların kendisine verdiği oçüde yetkilere sahiptir. Topluluklar için bütün uluslararası orgüuler için geçerli olan sinirlı yetki prensibi geçerlidir bu durum AT ạnlaşmasının $3 \mathrm{~b}$ md.'si tarafından da teyit edilmektedir.

AT anlaşmasının 235. md.'si ışı̆ıında muayyen koşullar altında Konsey kararı ile anlaşmanın yeţkiye ilişkin boşluklarının doldurulması mümkündür. Bu hüküm sınırlı yetki prensibinin aşılması değil, sınırlı yetki prensibinin esnekleştirilmesidir. 
Bu hükmün gerektiği gibi uygulanması konusunda Federal Anayasa Mahkemesinin Maastricht kararında ima ettiği gibi tereddüt bulunmaktadır. Topluluğun 235. md. muvacehesinde yetkilerini aşması konusu şimdiye dek bir dava konusu olmamışur. Bu durum 235 md. göre Konsey kararlannın potansiyel davacıların iradesi ile, ozellikle tüm Konsey üyelerinin oybirliği ile alınmasından ileri gelmektedir.

Topluluğu uluslararası kuruluşlardan ayıran nedir? ona anlaşmalarla verilen yetkilerin (yasama, yürütme ve yargı alanında) oblçỉ ve yoğunluğu mudur? Bu yetkiler geleneksel olarak devletlerin münhasır yetkileri içinde kalır. Bir devletin Avrupa Topluluğu'na katılması egemenlik alanına giren alanların onemli olçüde sınırlanması anlamını taşır.

Üye devletler ve Topluluklar arasındaki yetki dağılımının saptanmasında enstrüman anlaşmadır; anlaşmalar Topluluğun anayasasıdır. Her devlet kendi anayasasına bağlı olarak, Topluluklara yetki devrinde ve kendi yetkilerinin bu paralelde sınırlanmasında bir anayasal dayanak ihtiyacı içindedir. Bu çerçevede Ispanya Hukuk düzeninde Anayasanın 93. md.si Alman Hukuk düzeninde Anayasanın 23. md.si iyi bir ornek teşkil etmektedir.

Söz konusu dayanak ilgili devlet için yeterli midir? Bu dayanağın kapsamı nedir? Bu sorular tabiki ulusal anayasaya göre cevaplandırılabilir. Orneğin Ispanyol Anayasa mahkemesi 1.7.1992 tarihli, Anayasanın 93. md.'sine ilişkin mütalâasında, bu md.'nin Avrupa Birliłgi'ne ilişkin Maastricht anlaşmasının onaylanması bakımından yeterli bir dayanak oluşturmadığını, zira anlaşmanın Avrupa Birliği yurttaşlarına Anayasanın sadece Ispanyol vatandaşlarına saklı tutulan haklan tanıdığını ifade etmiştir. Bu mütalaa Ispanyol Anayasasının değiştirilmesi ve bilahare Maastricht anlaşmasının onaylanmasına imkan vermiştir (EuGRZ 1993, 285). Federal Alman Anayasa Mahkemesi 12.10.1993 tarihli Maastricht kararında (EuGRZ 1993, 429) ise GG'in Almanya'nın Avrupa Birligi'ne katılması için yeterli bir dayanak içerdiğini ifade etmiştir.

Ancak bütün bu kararlar Toplulukların yetkilerinin dayanağının ulusal anayasalar olduğu sonucunu vermez. Topluluk yetkilileri ve buna uygun olarak Topluluk ve ủye devletler arasında yapılan yetki dağılımı daha çok kendi dayanağını Topluluk anlaşmalarında bulmaktadır. Bu anlaşmalann yorumu münhasıran ATAD'a aittir. Topluluk yetki alanlanının üye devletlerin yetki alanlarından sınırlanması da buna dahildir.

Topluluk ve üye devletler arasında yetki uyuşmazlıkları anayasa uyuşmazlığı değildır. Bu uyuşmazlıkların karara bağlanması için iki yöntem vardır. Iptal davası (üye devletlerin Topluluk tasarruflarına karşı açı̆̆ı) ve anlaşma ihlali prosedürüdür (Komisyon veya bir devletin başka bir devlete karşı anlaşmadan doğan yükümlülüklerinin ihlali nedeniyle, -bu yükümlülüklere şüphesiz anlaşmalarla Topluluklara bırakılabilen yetkilere saygı dahildir- dava açılır).

ATAD'in bu tür yctki uyuşmazlıklarında mühnasır yetkisi Federal Alman Anayasa Mahkemesinin Maastricht kararında tereddüt konusu olmuştur. Kararda Anayasa Mahkemesi, Topluluk organ ve kurumlarının hukuki tasarruflarının kendilerine verilen egemenlik sınırları içinde kalıp kalmadıklanını veya bu sınırlan aşıp aşmadıklarını denetleme yetkisini mahfuz tutmuştur. Yetki aşımı sỏz konusu olduğu nispette Topluluk tasarruflan Alman ulusal egemenlik alanında geçerli olmayacaktır. 
Bu şekilde Federal Alman Anayasa Mahkemesi Topluluk tasarruflan bakımından bir denetim yetkisi iddia etmektedir. Bu tutum yeni değildir. Federal Alman Anayasa mahkemesi daha once de bu tür denetim yetkisi iddia etmiştir. Federal Alman Anayasa Mahkemesi örneğin Kloppenburg kararında (8.4.1987 tarihli karar, 2 BvR 687/85, BVerfGE 75, 223 = EuGRZ 1988, 113), her ne kadar sonuç olarak Topluluk yanlısı bir tutum sergilemişse de, detayh bir şekilde ATAD'ın direktiflerin doğrudan etkisi ile ilgili kararının hukuk yaratılmasında caiz olan sının aşt̆łıını dile getirmiştir.

Anayasanın üstünlüğünü temin etmekle görevli anayasa mahkemesinin anayasal prensipleri ihlal eden Topluluk tasarrufları bakımından rezerv sahibi olması doğaldır. Ancak bð̧yle bir rezerv Topluluk hukukunun onceliģi ile bağdaşmaz.

Extrem bir durumun söz konusu olması ve ATAD'ın bu tür yetki aşımlarını onaylaması durumunda Solange II karannda ifade edilen çekince geçerlilik kazanacaktır (22 Ekim 1986 tarihli karar, 2 BVR 197/83, BVerfGE 73, $339=$ EuGRZ 1987, 10). Avrupa Toplulukları, ozellikle Divan Topluluklar tarafından kullanılan egemenlik yetkileri bakımından genel olarak temel hakların etkin olarak korunmasını temin ettikçe, GG tarafindan ongörülen teminata özünde benzer bir saygı gősterdikçe, temel hakların ozünü temin ettiği nispette Federal Anayasa Mahkemesi yargı yetkisini istihraç edilen Topluluk hukuku bakımından (Bu hukuk Alman mahkemelerinin, mercilerinin ulusal egemenlik alanındaki tasarruflanna dayanak olmaktadır) kullanmayacak ve bu hukuku GG'in temel hak olçülerine göre olçmeyecektir; GG 100. md./l'e göre yapulan başvurular caiz kabul edilmeyecektir. Bunun tersi olan bir durumda Anayasa Mahkemesi Topluluk tasarruflarını denetleme hakkını mahfuz tutmaktadır.

Işte Federal Anayasa Mahkemesi Maastricht kararında ATAD tarafından yapılan yorumların sistematik olarak denetimini yapma hakkını bu çerçevede saklı tutmaktadır. $\mathrm{Bu}$ ise Topluluk anayasasının temel unsurlarına müdahale anlamını taşır. ATAD yorumlannın denetlenmesi iddiası Topluluk hukukunun muhtariyetini ve Topluluk hukuk yargısını inkar etmek sonucunu dogurur ve Topluluk hukukunun birliğini tehlikeye sokar. Ulrich Everling'in beliruiği gibi Federal Alman Anayasa Mahkemesinin Toplulukta ozzel bir statü iddia etmesi mümkün defildir. (Everling, BVerfG und Gerichtshof der Europäischen Gemeinschaften. Nach dem Maastricht Urteil, In Gedächtnisschrift für Eberhard Grabitz, München 1995, S. 57, 71) Federal Alman Anayasa Mahkemesi tarafindan sergilenen bu tutumun diger üye devletlerin Anayasa mahkemeleri yahut yüksek mahkemeleri tarafından takip edilmesi ve bu mahkemelerin ATAD kararlarını kendi ulusal egemenlik alanlanında değişik anayasa prensipleri, deger yargılan, yorum yőntemleri ile denetlemesi sistemi temelinden sarsabilir. Bu durum Topluluk anlaşmaları tarafından öngörülen Topluluk hukukunun sonu olacak ve Topluluğun fonksiyon yeteneği bakımından gerekli görülen, tüm üye devletlerde onay veya herhangi bir ulusal işbirliği olmaksızın Topluluk hukukunun doğrudan uygulanmasını sona erdirecektir. Bu uygulama Topluluk hukukunun uygulanmasında açık yahut zımni olarak üye devletlerin onayını beraberinde getirecektir. Bu yetki parlamentoda değil, ilgili yüksek mahkemede olacaktır. Böyle bir durumda Topluluk anlaşmalannın anayasa karakteri sona erecektir. 


\section{Topluluk Anayasa hukuku materyali}

Topluluk Anayasa hukuku sadece anlaşmalarla sınırlı değildir. Üye devletlerin hukuk düzenlerinde ortak olan genel hukuk prensiplerini de kapsamaktadir.

\section{Anayasa hukuku karakterli anlaşma normları}

Ilk etapta ATAD kararlan ile de teyit edildił̌i üzere, Topluluk anayasa hukukunun çekirde gini oluşuran AT anlaşmasına deģinelim. 1974'ten beri (21 Haziran ve 12 Aralık tarihli Reyners ve Walrave kararlanndan) AT anlaşmasının 52 ve 59. md. Uye devletler için sadece iktisat politikasına ilişkin davranış talimat olmayıp, aynı zamanda ortak pazardaki vatandaşlar için temel ozgürlukleri teminat altuna almaktadır. ATAD Walrave kararında 59. md.'nin mahkemelerin teminat aluna alacağı bireysel haklar tesis ettiğini vurgulamışur. (Walrave, Slg. 1974, 1405)

Malların serbest dolaşımı bakımından Divan 13.12.1991 tarihli GB -Inno- BM karannda $30 \mathrm{md}$.'den ulusal onlemlere karşı bir dava yolu istihraç etmiştir. (Rs. 18/88, Slg. 1991, I-5941) Bu ekonomik olarak yönlendirilmiş ozgürlük hakları pazar vatandaşları tarafından Topluluk organlanının tasarruflanna karşı da iddia edilebilir ve Divan tarafından Topluluğun yasama tasamuflarının denetiminde esas alınabilir.

Bu çerçevede 119. md.'de yer alan eşitlik prensibinin Topluluk anayasa hukuku normu olarak zikredilmesi gerekir. 15.06.1978 tarihli Defrenne karan Topluluk anayasa hukukunun gelişmesinde onemli bir đönemeçtir. Bu durum, Divan tarafından ücret alanında vurgulanan dolaylı mağduriyet konsepti bakımından da geçerlidir. (Krşt: 15.06.1978, Rs. 14977 ve Defrenne III. Slg. 1978, 1365 = EuGRZ 1978, 358)

AT anlaşmasının 5. md.'de Topluluk ve üye devletler arasında sadakat prensibine göre işbirlił̣̌i yükümlülüğ̛u ongớrülmektedir. Bu hüküm ATAD'ın içtihau ile anayasal bir boyut kazanmışur. 5 . md.'nin onemini Divan adli yardım çerçevesinde verdiği 12.7.1990 tarihli karan ile vurgulamışur. (Rs. C-2/88 1mm., Zwartveld u.a., Slg. 1990, I-3365; Krşt: 18.2.1992 tarihli karar, Rs. C-54/90)

AT anlaşmasının 3b md.'sinde yer alan subsidiarite prensibinin anayasa hukuku karakterini aynica konuşmaya gerek bulunmamaktadır. Ancak ATAD onnünde bu prensibin Topluluk organlan tarafından ihlal edildił̧i iddiası ile açılan bir davanın devam ettiģine işaret edilmesi gerekmektedir (Ingiltere Krallı̆̆ının Konseye karşı açı̆̆ı dava, Rs. C84/94; 93/104 sayılı direktifin (23.11.1993) (ABL.L.307, S. 18) subsidiarite prensibinin ihlali sonucunu doğurması iddiası). ATAD' In Keck/Mithovard karan (24.11.1993 tarihli karar, verb. Rs. C-267 ve 208/91, Slg. 1993, I-6097) hiçbir şekilde bu konuda gerekçe içermese de bu prensibin dolaylı olarak tanınması olarak değerlendirilmektedir.

Üye devletlerin ulusal birliğine saygı ( $A B$ anl. md. $F / 1$ ) yine bu çerçevede zikredilen bir anayasal prensiptir. Bu prensibin anayasa hukuku boyutu yeni değildir.

20.11.1984 tarihli Groener karannda ATAD (Rs. 379/87, Slg. 1989, 3967) Irlanda ulusal kimlik ve külttürünü açıkça vurgulamışur. Nihayet Para birlị̌̌i ile birlikte mütalaa eden prensiplere işaret edilmektedir. Çok tartı̧ılan Konvergenz kriterleri, ki bunlar ulusal seviyede kural olarak ekonomi politikası opsiyonlan olarak tanımlanmaktadır, Maastricht anlaşması ile Topluluk anayasa hukukunun temel aynılmaz parçası olmuştur (24.11.1993 
tarihli karar, verb. Rs. C-267 ve 268/91, Slg. 1993, I-6097). Özellikle Alman etkisi ile ortaya çıkan bu prensipler ekonomik nitelikli Topluluk anayasa normlarını ideolojik şekillenmesine neden olmuştur.

\section{Genel Hukuk Prensipleri}

Anayasa hukuku karakterine sahip anlaşma normlan yanısıra ATAD tarafından içtihatlannda geliştirilen anayasa hukuku karakterli genel hukuk ilkeleri vardır. Bunlann büyük bir kısmı büyük oneme sahiptir ve Topluluk hukukunun ius cogens karakterli normlan olarak kabul edilir.

Bu fundamental prensiplerin anayasa hukuku karakteri sadece Topluluk tasarruflarının onceliği bakımından değil, aynı zamanda ulusal mercilerin tasarrufları bakımından da ortaya çıkmaktadır (ulusal organların Topluluk düzenlemelerini icra etmeleri nispetinde) (11.7.1989 tarihli karar, Rs. 5/88, Wachauf, Slg. 1989, 2609).

ATAD sayısız davalarda Topluluk tüzüklerini hukuka olan güven prensibi ve orantulılık prensibine göre denetlemiştir. Orantılılık prensibi bunun dışında Birlik anlaşmasının 3b md.'si ile Avrupa Birliği anlaşmasına girmiştir (11.3.1987 tarihli karar, Verb. Rs. 279, 280, 285 ve 286/84, Rau/Kommission, Slg. 1987, $1069=$ EuGRZ 1988, 397, Nr. 2).

Genel hukuk prensipleri kategorisi içinde bireysel temel hakların korunmasına matuf olanlar büyük ơneme sahiptir. Zira Topluluk hukuk düzeninde açıkta, yazılı bir şekilde tanınmıs temel hak kataloğu bulunmamaktadır. Temel hakların Topluluk genel hukuk prensiplerine dahil edilmesi Divan tarafından üye devletlerin ortak anayasa gelenekleri ve üye devletlerin taraf oldukları anlaşmalar muvacehesinde gerçekleşmiştir. Divan 13.12.1979 tarihli Hauer kararında bu alandaki içtihatını şu şekilde formüle etmiştir (Rs. 44/79, SIg. 1979, 3727, Rdnm. 14, 15 = EuGRZ 1979, 661 f): "Topluluk organlarının tasarruflarıyla temel hakların ihlali sorunu Topluluk hukuku dışında değerlendirilemez; Üye devletlerden birinin yasama yahut anayasa düzenine bağlı deģerlendirme kriterleri Topluluk hukukunun materyal birliğini ve etkinliğini zarara sokar ve ortak pazar'ın kaçınılmaz olarak zarar görmesine ve Topluluğun tehlikeye girmesine neden olur. Temel haklar Divanın korumak zorunda olduğu genel hukuk prensiplerine dahildir. Bu hakların teminatunda Divan üye devletierin ortak anayasa geleneklerinden hareket eder. Bu şekilde Toplulukta üye devletlerin anayasalan ile teminat altuna alınan temel haklarla uyuşmayan hị̧ bir önlem hukuki olarak görülemez. Aynı şekilde üye devletlerin taraf oldukları yahut katıldıkları insan haklarına ilişkin DH anlaşmaları da Topluluk hukuku çerçevesinde dikkate alınır".

Divanın temel haklara ilişkin içtihatı Avrupa Birliği anlaşmasının $F / 2$ maddesi ile açıkça üstlenilmiştir. Bu hüküm Divanın içtihatlarının Topluluk anayasa hukukunda teyidi anlamını taşımakıadır. Aynı anlaşmanın L maddesi F maddesini Divanın yargı yetkisinin dışında bırakmışur.

Göz ardı edilmemesi gereken husus, Topluluk hukuku çerçevesinde temel hak teminatının zaman içinde kendi ağırlı̆ını kazanmıs olmasıdır. Bunun anlamı bir taraftan, Topluluk hukuku seviyesinde temel hakların bir temel hak kataloğuna istinat etmemesi, diğer taraftan bireyler için bu gelişmeden muhtar hakların doğmuş olmasıdır. Bu haklar muayyen koşullar altunda ulusal mahkemeler tarafından temin edilmektedir. 


\section{Topluluk anayasasının sınırları}

Şimdiye dek Topluluk anlaşmalarının anayasa hukuku karakteri üzerinde durduk. Şimdi anayasa hukukunun sınırlarına işaret edilecektir.

\section{Devletler Hukuku yaklaşımı}

Anlaşmaların DH karakteri ozellikle kriz zamanlarında açık bir şekilde ortaya çıkmaktadır. Danimarka Referandumunun olumsuz olarak sonuçlanmasıyla ortaya çıkan kriz, tüm üye devletlerin ortak iradeleriyle 11 ve 12.12 .1992 de kararlaşurılan sonuçlardan, eklerden ve $A B$ anlaşmasının getirdiği yükümlülüklerden Danimarka'nın muaf tutulmasıyla aşılmışur. Danimarka'nın Birlik içinde kalmasına imkan veren bu enstrumanlar DH tabiatlıdır. (ABL. C 348, 31.12.1992, S. 1).

Topluluktan tek taraflı çekilme yoktur. Ne Topluluk hukukunun yorumu, ne de genel DH Topluluktan tek taraflı çekilmeye izin vermektedir. Istisnai durum olarak Viyana anlaşmalar hukuku sözleşmesinin $60 / 2 \mathrm{md}$.'si, çok taraflı bir anlaşmanın ơnemli bir şekilde ihlalini, diğer anlaşma tarafı bakımından anlaşmayı tamamen yahut kısmen askıya alma veya anlaşmayı sona erdirme sebebi olarak görmektedir. 62. md. ise akdin inikâdı esnasındaki koşullarda esashı değişikliklerden söz etmektedir. Bu durum da anlaşmayı sona erdirme veya anlaşmadan çekilme bakamından bir sebep teşkil etmektedir. Ancak bu sebeplerin Topluluk anlaşması bakımından ortaya çıkmayacağı ümit edilmektedir.

Siyasi bakımdan ancak bir üye devlet, hükümetinin karşı iradesine veya halkının karşı iradesine rağmen Toplulukta kalmaya zorlanamaz. Böyle bir durumun ortaya çıkması halinde yine bu çekilmenin temini bir DH enstrümanının kullanılmasını gerektirecektir.

\section{Anayasa Hukuk Yaklaşımı}

Topluluk anlaşmaları sadece yürürlüğge girmeleri için değil, değiştirilmesi bakımından da tüm üye devletlerin onayını gerektiren anlaşmalardır.

Diğer bir ifade ile Toplulukta anlaşma yapma yetkisi üye devletlerde kalmışur. Anlaşma yapma yetkisinin üye devletlerde kalması nedeniyle entegrasyon prozesinde yapılacak her ơnemli değişikliğin, her bir üye devlette ulusal anayasa ölçülerine göre değerlendirilmesini gerektirmektedir. Bu durum $\mathrm{AB}$ anlaşmasının onaylanmasından önce üye devletlerin anayasalarında yapılan değişikliklerle yaşanmışur.

Topluluk anayasasının bir diğer özelliği, 1965'de Ophüls'ın belirttił̧i gibi (Carl Friedrich Ophüls, Eie Europäische Gemeinschaftsverträge als Planungsverfassungen in: Kaiser, Planung I, Recht und Politik der Planung in Wirtschaft und Gesellschaft 1965, S. 229) bu anlaşmaların konusunun bir entegrasyon prozesi olmasıdır. Bu prozesin nihai amacı ne hukuken ne de siyasi olarak saptanmıştır; nihai amaç halkların yakınlaşurılmasıdır. Bu nihai amaç ancak yeterli açıklıkta yazılmamışır. 
Buna karşılık ekonomi politikası amaçlarının ozellikle Roma anlaşmasına göre ortak pazann, Tek Senede göre iç pazann kurulması ile gerçekleştirilmesi óngörülmüşsïr. (ABL. L. 169, 29 juni 1987, S. 1).

\section{Birlik anlaşmasının özellikleri}

Maastricht anlaşması da, Avrupa Birliği anlaşması ismini taşımakla beraber, kendini siyasi birlik olarak tanımlamamaktadır. 7.2.1992 tarihli anlaşma yeni yetkiler yaratmış, yeni politikalar öngörmüş ve Birliğin birlikteliğini teşvik etmiştir.

Anlaşmada Parlamento için muayyen hukuku tasarruflar için işbirliği prosedüri yanısıra, yeni bir yőntem ongőrülmüş ve bir şekilde demokrasi unsurunun Toplulukta güçlenmesi istenmiştir.

Avrupa Birlił̣̆i'nin 3 ayağından birini teşkil AT anlaşması ağırlıklı olarak ekonomik alana eğilmiştir. $\mathrm{AB}$ anlaşmasında yeni olarak hukuken tam olarak belirtilmiş bir amaç ortaya konulmuştur: Bir ekonomi ve para birliğinin bir kuramsal destek ile Avrupa Merkez Bankası- kurulması óngobrülmüştür. 8. md. yer alan Birlik yurttaşlı̆̆ının hukuki anlamının görmezlikten gelinmesi mümkün değildir. Bu düzenleme,Birlik anlaşmasının politik açıdan en marjinal boyutunu teşkil etmektedir. Entegrasyon prozesini one gőtürmek için gerekli olan her sıçrama için bu prozesin başındaki siyasi iradenin yenilenmesi gerekmektedir. Entegrasyon prozesinin nihai amacının ne olduğu konusunda hükümetlerarası konferansa federalistler ve antifederalist görüş sahipleri arasında görüş farklılıkları ortaya çıkmaktadır.

\section{Yeni cografi boyut}

Topluluk anayasasının bir diğer özelliği de genişleyebileceği coğrafi alanın belirsizliğidir. Doğu Avrupa ülkelerinde son yıllarda meydana gelen gelişmelerle Topluluğun ilerideki gelişmelere ilişkin perspektifi tamamen değişmiştir.

\section{Demokratik meşruiyet sorunu}

Topluluk anayasası anlaşmaların parlamentolarca onaylanması ile üye devletlerde demokratik bir meşruiyet kazanmışur. Topluluk anayasasının demokratik meşruiyeti politik açıdan üye devletlerin ve halklannın görüşünden kaynaklanmaktadır. Topluluk organlari tarafindan kullanilan egemenlik yetkisi halktan kaynaklanmamakta, devletlerin temin ettiği yetkilerden oluşmaktadır. (Dieter Grimm, Braucht Europa eine Verfassung München, Carl-Friedrich -von Siemens- Stiftung, 1995, Themen Bd. 60, S. 32).

Topluluk anayasası ulusal anayasadan farkh yapı ve özelliklere sahiptir. Topluluk bir siyasi yapıdır ve ulusal bir devlet ile karşılaştunlamaz. Buna ilave olarak Topluluk yepyeni bir hukukî konstrüksiyondur ve hukuku ulusal hukuk ve DH arasında yer almaktadır.

Bir devletin anayasası ile karşılaşurılan Topluluk anayasasında doğrudan bir demokratik meşruiyet eksikliği vardır. Bu fark goz ardı edilemeyeceği gibi, mübalâa da edilmemelidir. Bu sebeple demokratik meşruiyetin sadece bir devlet yapısında olabileceği, buna karş̧ilık uluslarüstü bir yapıda olamayacağı şeklinde acele bir tez ortaya atmamak 
gerekir. Demokrasinin sadece devlet yapısı içinde olabileceği, uluslararası bir yapıda fonksiyonunu gősteremeyeceł̆i iddiası ampirik bir tanı olmayıp, dogmatik bir onyargıdır.

Demokratik meşruiyet, halkın temsilcilerini seçimi ile son bulmaz, başka deł̌gerler de içerir. Ömeğin, şeffaflık, azınlıkların korunması, yőnetimin etkin denetimi bu değerler arasında yer alır; doğrudan demokrasiyi meşruiyetin tek koşulu yapan tezin, rezervli olarak değerlendirilmesi gerekir. Toplulukta kısmen görüldüğỉ üzere dolaylı demokrasi kayıtsız şartsız yetersiz olarak kabul edilemez. Ulus devletlerde de dolaylı demokrasinin ornekleri vardır. Ama buna rağmen demokrasi eksikliǧinden sőz edilmemektedir. Demokrasi eksikliğinin sebebi ne olursa olsun, problemlerin sadece Toplulukla sinırlı olmadığını bilmek gerekmektedir.

Avrupa Parlamentosu Avrupa seviyesinde şimdiye dek olduğundan daha çok demokratiktir. Bunụn için tâbi daha çok yetkilere gereksinimi vardur. Toplulư̧un demokratik meşruiyetinin ulusal parlamentoların Topluluk seviyesinde daha etkin olması ile güçlenebileceği tezine ise inanmak zor gözükmektedir. Ulusal parlamentoların katılımında muayyen bir sınırın ơtesine geçildiği takdirde, ortak bir tutum olasılıł̆ı oldukça sınırlanmış olur. Ulusal parlamentolar tâbi ki hükümetlerine karşı denetim yetkilerini (Bakanlar Konseyindeki tutumları bakımından) daha iyi kullanılabilir. (Federal meclisin bu olanağına Federal Anayasa Mahkemesi Maastricht kararında işaret etmektedir. BVerfGE 89, 155, 190f = EuGRZ 1993, 429, 439)

\section{Hukuk devleti prensibinin komponentleri}

Demokratik meşruiyet kavramı hukuk devleti prensibinin diger tamamlayıcı unsurlan (Komponentleri) olmaksızın düşünülemez. Idarenin tasarruflarının yargı denetimi demokrasi prensibinin gerekli bir tamamlayıcısıdır. Bu noktada Topluluğun hukuki devleti karakteri tartışlamaz.

Uygulamada ATAD 1953'den beri ve ilk derece mahkemesi 1989'dan beri bir anayasa ve idare mahkemesinin elementer fonksiyonlannı yerine getirmektedir. Topluluk seviyesinde her iki mahkeme üzerinden gerçekleştirilecek hukuk yollannı ulusal hukuk yollan ile karşılaştırmaya gerek bulunmamaktadır.

Hukuk devletinde, demokratik meşruiyet bir alternatif olmayıp, onun onemli bir elementidir. Bizim için Topluluklar bakımından ónemli olan, Topluluk anlaşmalarını ifade eden anayasa kavramının Topluluğu nitelendiren "hukuk devleti" özelliklerini dile getirmesidir. Bu hukuk devleti òzelliği Topluluğu diğer uluslararası kuruluşlardan ayırdetmektedir. Bu fark herşeyden önce Topluluk yargısının şekillendirilmesinde ortaya çikmaktadır.

Topluluk anayasasının önemli bir elementi olarak hukuk devleti niteliģi "Les Verts" karannda ortaya çıkmaktadır. Bu kararda Divan AT anlaşmasının anayasa karakterine istinaden Avrupa Parlamentosunun tasarruflarının yargı denetimine tabi olması gerektiğini kabul etmiştir (bu durum AT anlaşmasının 173. md. zikredilmediği halde). AT bir hukuk topluluğudur. Ne üye devletler ne de Topluluk organları, tasarruflarının Topluluk anayasası ile bağdaşıp bağdaşmadığını ortaya koymak bakımından denetim dışı kalabilir (Rs. 379/87, Slg. 1989, 3967). 
Avrupa Birlił̆i anlaşmasının 173. maddesi ile bu içtihata uyum sağlanmıştır. Topluluk yurttaşlarının durumu ve anlaşmanın siyasi amaçlan da anayasa kavramının kullanılmasını haklı kılmaktadır. Bu çerçevede Divanın Avrupa Ekonomik Alanına zikredilen görüşüne işaret etmek gerekmektedir. Bu görüşte, bu elementler Topluluk anlaşmalan ile diğer DH anlaşmaları arasındaki önemli farkhlık olarak zikredilmiştir.

\section{Sonuç}

Anayasa kavramının kullanılması Avrupa'daki bugünkü realite ışı̆̆ında sadece bir kelime oyunu mudur? yoksa Toplulukta gerçekten bu kavramın kullanılması uygun mudur? ikinci durumu kabul etmek dogru gózülkmektedir. Bu kavramın kullanılması bir taraftan Topluluk hukuk düzeninin onemli elementlerini vurgulamaktadır. Diger taraftan bu kavramın kullanılması herhangi bir ફsaşınlığa neden olmamakıadır. Zira nasıl ki Topluluğun bir devlet ile karşılaşurılması mümkün değilse, Topluluğun anayasası da temelde ulusal anayasalardan farkhidir.

Politik açıdan Topluluk anlaşmalarının anayasa karakteri problemlidir. Avrupa Parlamentosunun talep etmesine rağmen Topluluk seviyesinde şimdiye dek gerçek bir anayasa ihdası söz konusu olamamışur. Zikredildiği üzere herbir anlaşma değişikliğinde uluslararası yöntemler uygulanmı̧ ve bu durum böyle devam edecek gơnülmektedir.

Topluluk anayasasının geliştirilmesinde doğrudan bir demokratik işbirliğinin eksik olması, bir Avrupa halkının mevcut olmadığının ifadesinden başka birşey deł̌ildir. Avrupa halklarına iradelerini dile getirmek bakımindan uygun araçlar ongörülmemiştir. Şu anda bir Avrupa ulusal kimliği yoktur. Böyle bir kimliğin kısa bir zamanda oluşacağı da tasavvur edilememektedir. Böyle bir kimlik bir Avrupa devletinin ortaya çıkması bakımından ơn koşuldur. Ama bu, Topluluk anayasasının "demokratik meşruiyeti" için ön koşul değildir. 